\title{
Novedades en dermatitis atópica: ya están aquí los inhibidores de la JAK baricitinib y upadacitinib
}

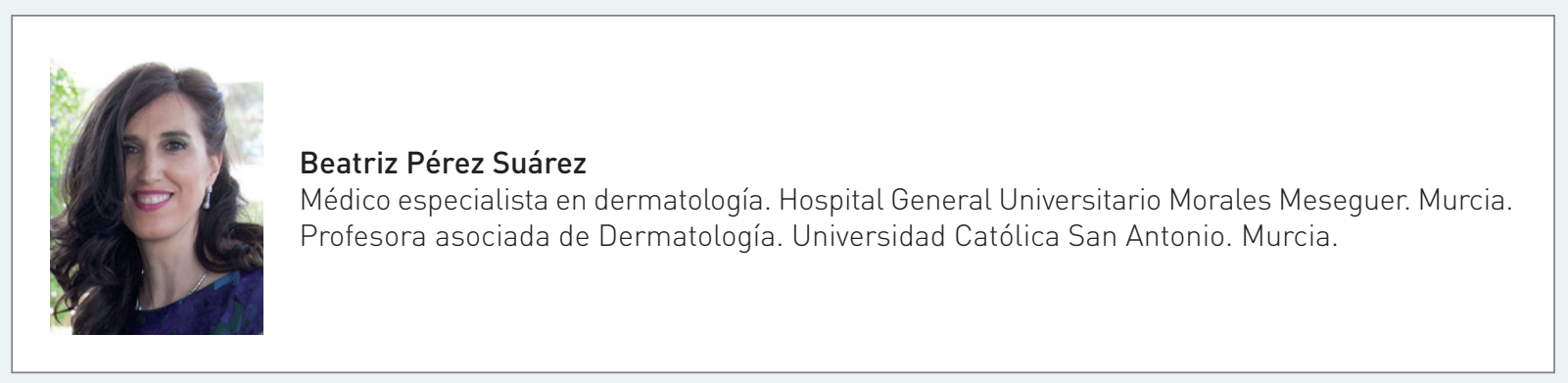

Hasta hace unos años, los dermatólogos teníamos dificultades a la hora de manejar los casos graves de dermatitis atópica (DA), ya que, además de los corticoides orales, únicamente la ciclosporina $A$ tenía indicación de uso para esta enfermedad. Afortunadamente, en los últimos tiempos, gracias al esfuerzo investigador de la industria farmacéutica, se está aumentando el arsenal terapéutico disponible para esta afección. Así, a finales de 2017, la Agencia Europea de Medicamentos (EMA; del inglés, European Medicines Agencyl dio luz verde a la comercialización en Europa del dupilumab', el primer anticuerpo monoclonal que inhibe las interleucinas IL-4 e IL-13 para el tratamiento de la DA moderada o grave. Más recientemente, la EMA ha aprobado el uso de los inhibidores de la cinasa de Jano (JAK; del inglés, Janus kinase) baricitinib² y upadacitinib ${ }^{3}$ para la DA en septiembre de 2020 y en agosto de 2021, respectivamente, lo que supone una importante novedad farmacológica para los dermatólogos.

La vía de señalización intracelular JAK/STAT - de las citocinas JAK y el transductor de señal y activador de la transcripción (STAT; del inglés, signal transducer and activator of transcription) - se activa cuando un ligando extracelular se une a un receptor transmembrana, dando, así, lugar a una cascada de señalización y regulación de genes. En la DA, hay una desregulación al alza en la vía JAK/STAT -fundamentalmente, de la JAK1, la JAK2, la JAK3 y la tirosina-cinasa 2 (TYK2; del inglés, tyrosine $k i$ nase 2) - , con un aumento de la respuesta mediada por los linfocitos $T$ colaboradores de tipo $2\left(T_{h} 2\right.$; del inglés, Thelper 2), supresión de linfocitos $T$ reguladores, activación de eosinófilos y liberación de citocinas proinflamatorias. Este aumento se asocia a la producción de IL-4, IL-5, IL-10 e IL-13, conduciendo a un deterioro de la barrera cutánea y al empeoramiento del prurito ${ }^{4}$.

El baricitinib es un inhibidor selectivo y reversible de las JAK1 y JAK2. La dosis oral recomendada para la DA en adultos es de $4 \mathrm{mg} /$ día, que puede reducirse a $2 \mathrm{mg} /$ día en pacientes mayores de 75 años o con antecedentes de infecciones crónicas o recurrentes. Como efectos adversos más frecuentes, se encuentran las infecciones (sobre todo, de las vías respiratorias altas), la elevación del colesterol transportado por lipoproteínas de baja densidad (LDL; del inglés, low-density lipoproteins) o las transaminasas, la cefalea, la trombocitosis y la 
neutropenia. Así, antes del inicio del tratamiento, se deberá descartar infección tuberculosa y realizar analítica con hemograma y bioquímica, y repetirla a las 12 semanas. También es recomendable que los pacientes hayan completado su pauta de vacunación ${ }^{2}$. En cuanto a la eficacia, en sus estudios pivotales BREEZE-AD1 y 2, se demostró una superioridad estadísticamente significativa del baricitinib frente al placebo, mejorando los síntomas y signos de la DA a las 16 semanas $^{5}$.

El upadacitinib es un potente inhibidor de la JAK1, la JAK2, la JAK3 y la TYK2. Tiene indicación en la DA moderada y grave para adultos y adolescentes a partir de los 12 años, con una dosis oral diaria recomendada entre 15 y 30 mg. Como efectos adversos más frecuentes, se encuentran el acné, las infecciones de las vías respiratorias altas, la cefalea, la elevación de la creatina-cinasa y la DA6. Antes del inicio del tratamiento y durante este, se recomienda la realización de pruebas de detección de tuberculosis y de hepatitis víricas, y hemograma y bioquímica con perfil hepático y lipídico ${ }^{3}$. Asimismo, es aconsejable completar la pauta de vacunación previa a la instauración del tratamiento. En sus estudios pivotales Measure Up 1 y 2, se demostró una superioridad estadísticamente significativa frente al placebo a las 16 semanas, medida tanto mediante el índice de intensidad y gravedad del eccema (EASI75; del inglés, Eczema Area and Severity Index), como con un resultado en la escala validada de evaluación global del investigador para la DA lvIGA-AD; del inglés, validated Investigator's Global Assessment for Atopic Der- matitis) limpio o casi limpio, y un perfil de beneficio-riesgo satisfactorio.

Así, estamos siendo testigos de una auténtica revolución terapéutica en el manejo de la DA. El desarrollo de fármacos que utilizan novedosos mecanismos de acción supondrá un hito en la historia de la dermatología y un importante avance en la calidad de vida de nuestros pacientes.

\section{BIBLIOGRAFÍA}

1. European Medicines Agency (EMA). Ficha técnica de Dupixent (DCI: dupilumab). Ámsterdam: EMA; 2021. Disponible en: https://www.ema.europa.eu/en/documents/productinformation/dupixent-epar-product-information_es.pdf

2. European Medicines Agency (EMA). Ficha técnica de Olumiant (DCl: baricitinib. Ámsterdam: EMA; 2020. Disponible en: https://www.ema.europa.eu/en/documents/productinformation/olumiant-epar-product-information_es.pdf

3. European Medicines Agency (EMA). Ficha técnica de Rinvoq (DCl: upadacitinib). Ámsterdam: EMA; 2021. Disponible en: https://www.ema.europa.eu/en/documents/product-information/rinvoq-epar-product-information_es.pdf

4. García-Melendo C, Cubiró X, Puig L. Inhibidores de JAK: usos en dermatología. Parte 2: aplicaciones en psoriasis, dermatitis atópica y otras dermatosis. Actas Dermosifiliogr. 2021;112(7):586-600.

5. Simpson EL, Lacour JP, Spelman L, Galimberti R, Eichenfield LF, Bissonnette R, et al. Baricitinib in patients with moderate-to-severe atopic dermatitis and inadequate response to topical corticosteroids: results from two randomized monotherapy phase III trials. Br J Dermatol. 2020; 183(2):242-55.

6. Gutterman-Yanssky E, Teixeira HD, Simpson EL, Papp KA, Pangan AL, Blauvelt A, et al. Once-daily upadacitinib versus placebo in adolescents and adults with moderate-to-severe atopic dermatitis (Measure Up 1 and Measure Up 2): results from two replicate double-blind, randomised controlled phase 3 trials. Lancet. 2021;397(10290):2151-68. 